
The development of databases that incorporate the various data sets for different renewable energy sources is a necessary step for resource assessment. NREL's Resource Information and Forecasting group determines the data elements or factors that are significant to a particular renewable energy generating technology, gathers the data pieces from a variety of different sources, generates data elements when needed (e.g. model estimates of solar fluxes from observed cloud amounts), and maintains these unique data pieces in databases that are specific to renewable energy. Data are frequently collected from the U.S. Geological Survey (USGS), U.S. Department of Agriculture (USDA), Environmental Protection Agency (EPA), the National Oceanic Atmospheric Administration (NOAA), as well as NREL's own measuring devices and resource models and the National Aeronautics and Space Administration (NASA).

The resulting resource databases are then used as key inputs to model energy conversion system performance (e.g., PVWatts for photovoltaic systems), building energy performance (e.g.,

\section{Analytical Tools and Websites}

PVWatts $^{\mathrm{TM}}$ Calculator estimates the electrical energy produced by grid-connected photovoltaic systems. www.nrel.gov/rredc/pvwatts/

Solar Advisor Model (SAM) allows users to investigate the impact of variations in physical, cost, and financial parameters to better understand their impact on key figures of merit. www.nrel.gov/analysis/sam

HOMER, the micropower optimization model, simplifies the task of evaluating design options for both off-grid and grid-connected power systems. https://analysis.nrel. gov/homer/

In My Backyard (IMBY) estimates the electricity you can produce with a solar PV array or wind turbine at your home or business. www.nrel.gov/eis/imby

Geospatial Toolkit is a map-based software application that integrates resource data and GIS for integrated resource assessment. www.nrel.gov/applying_technologies/ geospatial_toolkits.html

ViPOR, an optimization model for designing village electrification systems can determine which houses should be powered by isolated power systems and which should be included in a centralized distribution grid when given a map of a village and some information about load sizes and equipment costs. http://analysis.nrel.gov/vipor/

Renewable Resource Data Center: www.nrel.gov/rredc Measurement \& Instrumentation Data Center: www.nrel.gov/midc

Wind Resource Assessment: www.nrel.gov/wind/resource_assessment.html
BEopt for optimal building energy design), and resource characterizations (e.g., TMY typical meteorological year data sets).

\section{Who Uses Resource Information?}

Everyone associated with a renewable energy project has use for accurate, reliable, unbiased, resource information. Policy makers want to know where renewable generation projects are located and how they interconnect into the existing system. Developers want to know where to deploy renewable energy conversion systems and in what form. Engineers use resource information for system design and implementation strategies and scientists use the data for the development and validation of computer models used in atmospheric science and climate change research. System operators use resource information to maintain peak performance and provide customers with stable generation, and end users use it to determine energy generating capacity and installed system performance. Investors use resource information to evaluate the viability of investing in a project.

\section{Resource Forecasting}

The use of renewable resource forecasting is becoming a critical component in the operation of the electrical grid as more renewable energy generation is added. Because of the variability of energy production from weather-driven renewable technologies, the need for reliable short-term forecasting is essential to the optimization of renewable electricity generation and grid performance.

Researchers at NREL are working with the renewable energy industry to provide utilities and grid operation organizations with weather forecast techniques that incorporate meteorological data to predict renewable electrical generation. One of those techniques is mesoscale modeling. A familiar tool in weather forecasting, mesoscale modeling offers resource assessment potential for local and site-specific applications by simulating with reasonable accuracy, complex wind flows and cloud formations in areas where surface measurement are scant or non-existent.

\section{Working with Us}

Key resource questions must be answered to accelerate the deployment of renewable energy. NREL's researchers establish technology partnerships to conduct joint research, provide technical assistance, and perform testing. For more information, contact Tom Stoffel at Thomas.Stoffel@nrel.gov.



NREL is a national laboratory of the U.S. Department of Energy

Office of Energy Efficiency and Renewable Energy

Operated by the Alliance for Sustainable Energy, LLC

NREL/FS-550-46441 • November 2009

Printed with a renewable-source ink on paper containing at least $50 \%$ wastepaper, including $10 \%$ post consumer waste. 